\title{
Study on Effecting Parameters of Flat and Hemispherical end Tools in SPIF of Aluminium Foils
}

\author{
Sherwan Mohammed NAJM*, Imre PANITI
}

\begin{abstract}
Single Point Incremental Forming (SPIF) is a fast technique in the range of flexible prototype production without using a punch or die. Absence of the molding tools makes SPIF useful to form a complex product and these parts usually need different tool shapes. The aim of this study was to compare the performance of flat end and hemispherical end tools in micro-SPIF and evaluate the threshold value of the tool radius in relation to initial blank thickness. This paper investigated the best results of the final geometry, thickness homogeneity, minimum pillow surface, and maximum forming depth using different shapes and different sizes of the tool. The analysis of the results on AIMn1Mg1 foils with 0,22 mm initial thickness shows that the flat tool improves the geometry accuracy and decreases the pillow effect. Furthermore, in micro-ISF higher formability and more stable thickness distribution can be achieved with a flat end tool.
\end{abstract}

Keywords: aluminium alloy foils; flat tool; incremental forming; pillow surface; sheet forming; single point; SPIF

\section{INTRODUCTION}

Incremental Sheet Forming (ISF) is one of the moderate technologies in sheet forming, but it is not completely defined yet regarding the process parameters. The idea of Die-less incremental sheet forming was patented by Leszak [1], however the invention of Berghahn [2] has more similarities with the current one. In particular, incremental forming of the polymer was patented by Franzen et al. [3]. Recently, Karthik et al. [4] investigated different polymer materials formed by SPIF using roller ball tools to study variable process parameter. They mentioned the forming depth by the reliance on failure depends on the thinning of the component wall thickness. SPIF is one of the important main branches of incremental sheet forming since it is applied to form many different shapes. In the one hand, some of the formed parts are complex (e.g. a geometry with a sharp corner in the wall edges needs a different shape of tools without decreasing the forming depth or the geometrical accuracy), and thereby new application areas for this process are foreseen. On the other hand, it is necessary to improve or increase the properties of the product. Therefore, there is a need for more experimental investigation of the process from the view of the different geometry of the forming tool.

According to a review paper published by McAnulty et al. [5], the most tested parameter by researchers is the tool diameter. They count that 23 papers studied the effects of the tool diameter on formability. Of these, 10 reported that the tool diameter decrease lead to a decrease in formability, and the opposite effect showed in 7 papers; furthermore 6 mentioned that to reach maximum formability, optimization was necessary. For this reason, the tool effect behaviour is not completely determined, and it can be considered as still under exploration.

Afonso et al. claimed that to get a formed part with more precision, an adequate tool should be selected for each geometry [6]. Kumara et al. mentioned that the geometrical accuracy of the formed components in ISF has to be focused on in future work [7]. Hesse et al. reported that the formed parts of geometrical accuracy in ISF is less than those of traditional processes [8]. Single Point Incremental Forming "suffers" from poor geometry accuracy and to improve this is a challenge of this process [9-15]. Due to the higher formability, compared to conventional processes, SPIF drew great attention [12], [16]. Paniti and Viharos focused on the micro-ISF of aluminium foils to overcome the excessive thinning and crack by the necking of the sheet during the process [17]. They applied an indirect monitoring method using servo motor current measurements to follow the forming force and detect necking and cracks in real time. However, they mentioned the influence of other materials and geometries for sheets thinner than $0,5 \mathrm{~mm}$ needs to be studied. Usually SPIF is a manufacturing process of the sheet metal in which the sheet is formed in an incremental behaviour using a controlled tool by a CNC machine, and, usually, the tool has a hemispherical shape [18]. Ziran et al. investigated the effects of the tool size and tool shape on the formability and shape accuracy of the formed part of an AA-3003O aluminium sheet [19]. Two groups of tools, according to the tool end (flat and hemispherical), were used. The first group ( $1 \mathrm{~mm}, 2 \mathrm{~mm}$ and $3 \mathrm{~mm}$ ) had a corner radius of the flat end with a constant end diameter of $10 \mathrm{~mm}$, and the second group ( $4 \mathrm{~mm}, 6 \mathrm{~mm}$ and $10 \mathrm{~mm}$ ) with a radius for the hemispherical tool. They found better accuracy in the profile of the U-shaped channel obtained by the flat end tools than the hemispherical end tools. Furthermore, they reported that choosing a proper corner radius for the flat tool can increase the sheet formability. Kim and Park used three diameters for a hemispherical tool to form an aluminium 1050 sheet with a thickness of $0,3 \mathrm{~mm} \mathrm{[20].} \mathrm{The}$ results from their study was that the forming depth increased as the level of strain decreased due to the increase of the contact area between the tool head and the sheet, and the crack occurred $(5 \mathrm{~mm}, 10 \mathrm{~mm}$ and $15 \mathrm{~mm})$ at $6 \mathrm{~mm}$; $7,5 \mathrm{~mm}$, and 8,6 $\mathrm{mm}$ forming depth, respectively. Jeswiet et al. claimed that a high wall angle can be obtained by smaller tools but with a rougher surface [21]. On the contrary, others reported that the surface roughness improves as the tool diameter increases [22, 23]. Kurra and Regalla observed that by increasing the tool diameter and step depth a decrease in the formability occurs [24]. Centeno et al. formed stainless steel sheets using different (10 $\mathrm{mm}$ and $20 \mathrm{~mm}$ ) tool diameters and they noticed that necking followed by a ductile fracture was visible by 
utilizing a large tool diameter [25]. A fracture without necking was observed for the smallest tool diameter. AlGhamdi and Hussain attempted to find the threshold value of the tool radius $(R)$ in relation to blank thickness $\left(T_{\mathrm{B}}=1\right.$ $\mathrm{mm}$ in their case) in SPIF to improve the formability in fixed angle frustum [26]. The ratio of the tool radius and blank thickness varied between 1,1 to 3,9 to study the metal flow on the left side and on the right side of the formability diagram where the threshold value-which "has been observed to be independent of the material properties" was around 2,2 (indicating the maximum formability). It was reported that the formability increases by increasing the $R / T_{\mathrm{B}}$ ratio until the observed threshold value and afterwards it begins to drop. Moreover, they claimed that the use of small tools leads to metal squeezing and "undue" surface cutting. FE analyses showed that this occurs because the metal flows out of the blank plane, causing early weakening/thinning (like in the case of $R=1,1 T_{\mathrm{B}}$ ) leading to fractures.

The goal of this study is to investigate the effects of the tool shape and tool size on geometry accuracy, pillow effect, thickness distribution, and formability. AlMn1Mg1 foils with $0,22 \mathrm{~mm}$ initial thickness were used in all experiments. Furthermore, in this study, the evaluation of the above-mentioned threshold value has also investigated whether it is still valid in case of a thin sheet.

\section{MATERIAL PROPERTIES}

AlMn1Mg1 blanks of $180 \mathrm{~mm} \times 180 \mathrm{~mm} \times 0,22 \mathrm{~mm}$ were used for the Experimental tests. The mechanical properties of the blank sheet were measured from the tensile testing in $\left(0^{\circ}, 45^{\circ}, 90^{\circ}\right)$ of the rolling direction. The mechanical properties and chemical composition of the material are shown in Tab. 1 and Tab. 2.

Table 1 Mechanical Properties

\begin{tabular}{|c|c|c|c|c|c|}
\hline Direction & Yield strength / MPa & Ultimate tensile strength / MPa & Elongation $/ \%$ & Elongation $A_{50} / \%$ & $n_{5}$ \\
\hline $0^{0}$ & 88,3 & 183,0 & 16,44 & 16,88 & 0,297 \\
\hline $45^{0}$ & 90,0 & 155,5 & 9,27 & 0,554 \\
\hline $90^{0}$ & 86,3 & 170,3 & 12,48 & 0,45 & 12,95 \\
\hline
\end{tabular}

Table 2 Chemical Composition

\begin{tabular}{|c|c|c|c|c|c|c|c|c|c|}
\hline $\mathrm{Al}$ & $\mathrm{Si}$ & $\mathrm{Fe}$ & $\mathrm{Cu}$ & $\mathrm{Mn}$ & $\mathrm{Mg}$ & $\mathrm{Zn}$ & $\mathrm{Cr}$ & $\mathrm{Ni}$ & $\mathrm{Others}$ \\
\hline 96,90 & 0,201 & 0,448 & 0,212 & 0,807 & 1,260 & 0,071 & 0,022 & 0,006 & 0,073 \\
\hline
\end{tabular}

\section{EXPERIMENTS}

All the experimental tests were performed using a Linux CNC real-time controller in a 3-axis Rieckhoff CNC milling machine. The applied machine and rig are shown in Fig. 1.

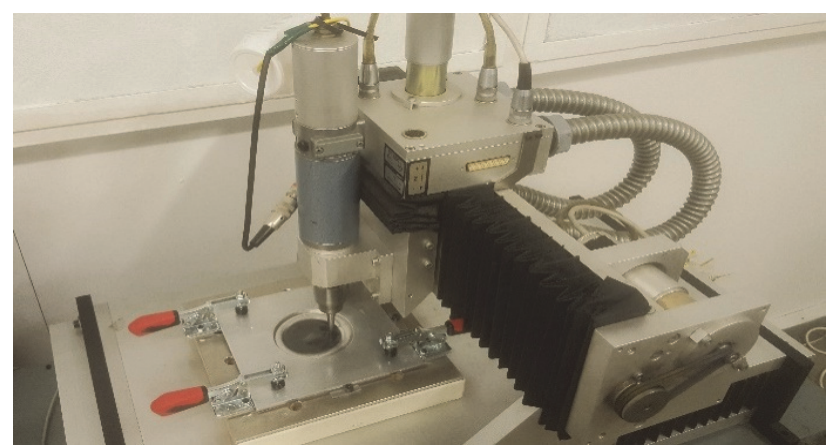

Figure 1 Rieckhoff CNC milling machine and rig
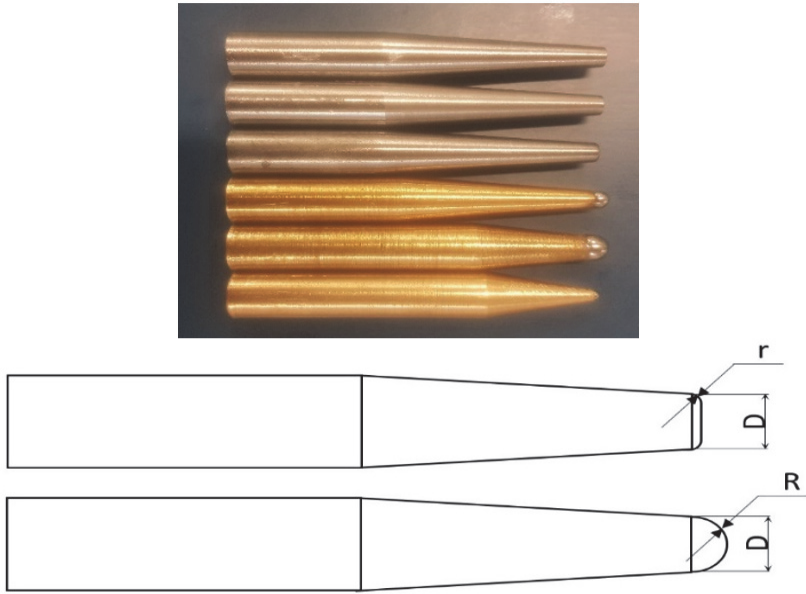

Figure 2 Tools Used and Geometrical Sketch
Two sets of tools (Flat end tool and Hemispherical end tool) were used to form the blank sheet. The Tools sets and sketches of the tools are shown in Fig. 2.

The constant diameter $(D)$ was used for the flat end tool with different corner radi $(r)$, and a different diameter of the hemispherical tool was employed to form a frustum cone with arched walls, as shown in Fig. 3.

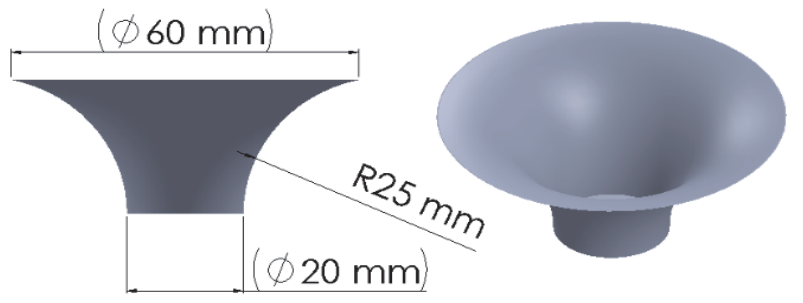

Figure $3 \mathrm{CAD}$ model of the formed components

To study the effect of the two types of forming tools on the (geometry accuracy, pillow effect, thickness homogeneity, and formability in terms of maximum depth) all other parameters of the process (step size, feed rate, and spindle speed) have been fixed. The value of the mentioned parameters and the geometrical properties of the tools are listed in Tab. 3. A helical tool path was used, and machine oil was applied for lubrication at the forming process.

Table 3 Process parameters and tool geometric details

\begin{tabular}{|c|c|c|c|}
\hline $\begin{array}{c}\text { Experimental Process } \\
\text { Parameters }\end{array}$ & \multirow{2}{*}{ Tool } & \multicolumn{2}{|c|}{ Geometry } \\
\hline \multirow{7}{*}{$\begin{array}{l}\text { Sheet Thickness }=0,22 \mathrm{~mm} \\
\text { Step Size }=0,01 \mathrm{~mm} \\
\text { Feed Rate }=1500 \mathrm{~mm} / \mathrm{min} \\
\text { Spindle Speed }=3000 \mathrm{rpm}\end{array}$} & & $\begin{array}{l}r / \mathrm{mm} \\
R / \mathrm{mm}\end{array}$ & $D / \mathrm{mm}$ \\
\hline & \multirow{3}{*}{ Flat end } & 0,1 & 4 \\
\hline & & 0,3 & 4 \\
\hline & & 0,5 & 4 \\
\hline & \multirow{3}{*}{$\begin{array}{l}\text { Hemispherical } \\
\text { end }\end{array}$} & 1 & 2 \\
\hline & & 2 & 4 \\
\hline & & 3 & 6 \\
\hline
\end{tabular}


Three components were formed for each tool to calculate the average of the measured parameters. Fig. 4 shows samples of the formed components.

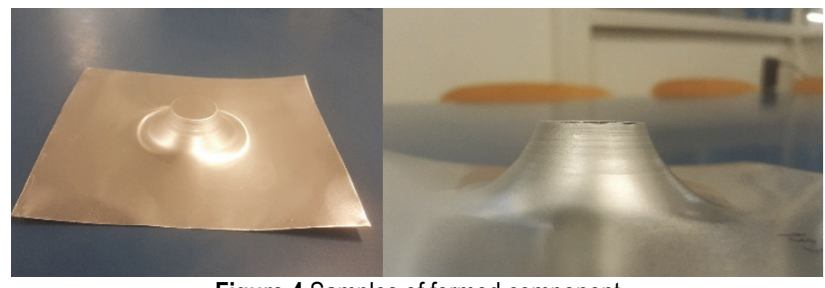

Figure 4 Samples of formed component

\subsection{Investigation on Geometry Accuracy}

A Mitutoyo Coordinate Measuring Machine Euro-CA776 (CMM) was used with maximum uncertainty $5 \mu \mathrm{m}$, as shown in Fig. 5, to measure the profile of the formed component.

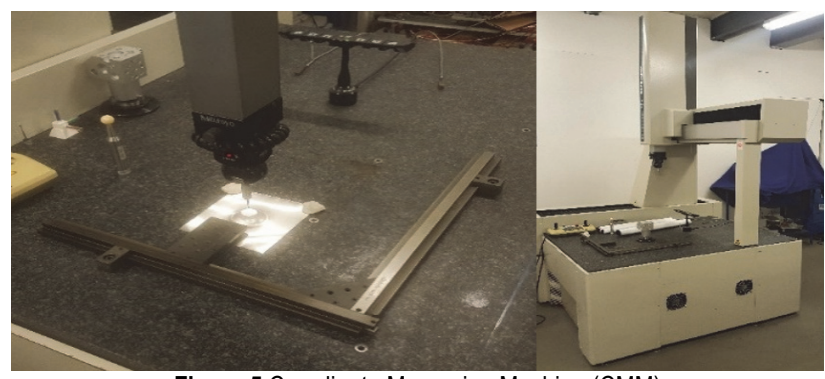

Figure 5 Coordinate Measuring Machine (CMM)

The accuracy of the geometry and the deviations from the desired shape were directly measured from the CMM to study the effects of the tool type on the component accuracy. The component errors that might occur during the process are illustrated in Fig. 6.

\subsection{Investigation on Pillow Effects}

A Digimatic dial indicator with one-micron precision was used to measure the pillow surface that was affected by different tools. The pillow effect is illustrated on the bottom of the formed part in Fig. 6 .

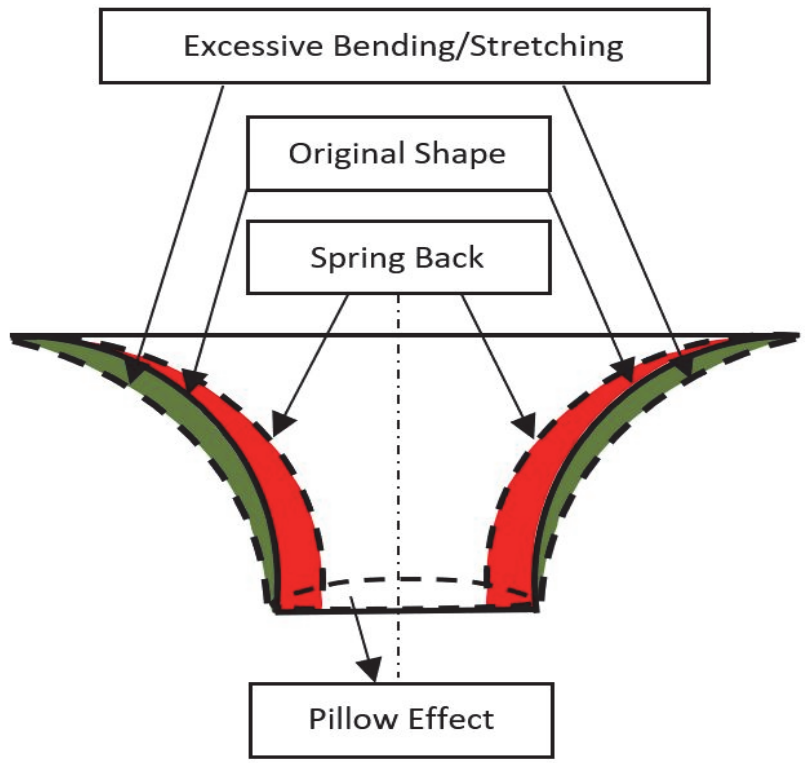

Figure 6 Component errors

\subsection{Investigation on Thickness Homogeneity}

The thickness distribution along the wall of the formed component is one of the SPIF control problems. Figuratively, it can be said that it is impossible to get the same value of the thickness along the formed wall, because the thickness usually satisfies the sine law: $t=t_{0} \times \sin (90$ $\theta)$ [27], where $(t)$ is the formed wall thickness, $\left(t_{0}\right)$ is the initial wall thickness, and $(\theta)$ is the wall angle, but it is also meaningful to make a stable decreasing thickness value. A digital micrometre was applied to measure the thickness affected by the tools.

\subsection{Investigation on Formability}

The formability in SPIF is a result of the biaxial or plane strain flow of the sheet materials due to the stretching and bending in the direction of the tool. The term of more materials flowing means a higher forming depth adopted to consider the forming depth, as indicating the formability [28].

\section{RESULTS AND DISCUSSIN \\ 4.1 Geometry Accuracy}

Fifteen points for each sample were taken to measure the geometry by CMM, and, calculating the deviation of each point of the formed wall from the desired geometry. It was found that the largest deviation of the geometry visible in the components is formed by Hemispherical end tools set with a $6 \mathrm{~mm}$ in tool diameter (see Fig. 7).

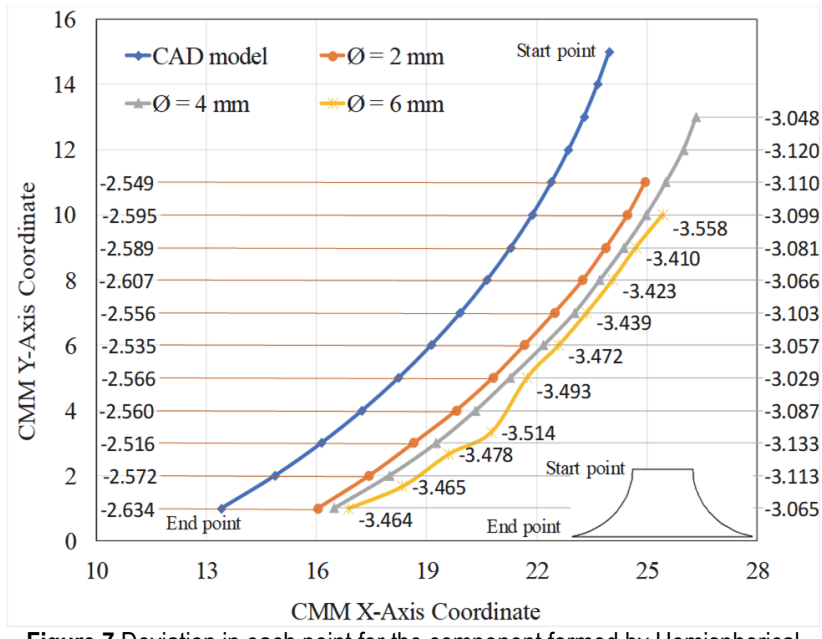

Figure 7 Deviation in each point for the component formed by Hemispherical end tools set

The minimum deviation occurred by using a Flat end tool with a $0,1 \mathrm{~mm}$ corner radius (see Fig. 8 ). The accuracy of the formed part using a Flat end tool decreased the deviation by $43 \%$ compared to the parts formed by a Hemispherical end tool (see Fig. 9). All the deviations that happened in the components formed using both sets of tools are due to springback except the component formed by a $0,1 \mathrm{~mm}$ Flat end tool, which is caused by excessive bending/stretching. 


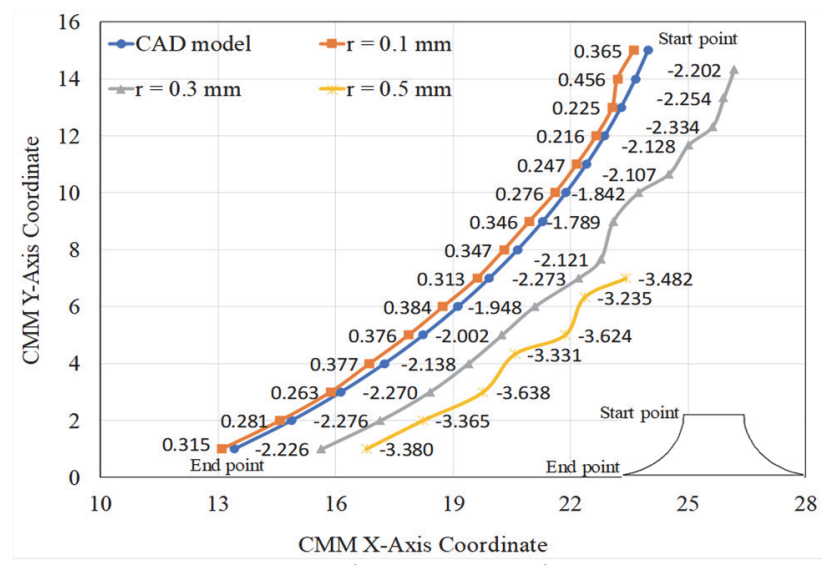

Figure 8 Deviation in each point for the component formed by Flat end tools set

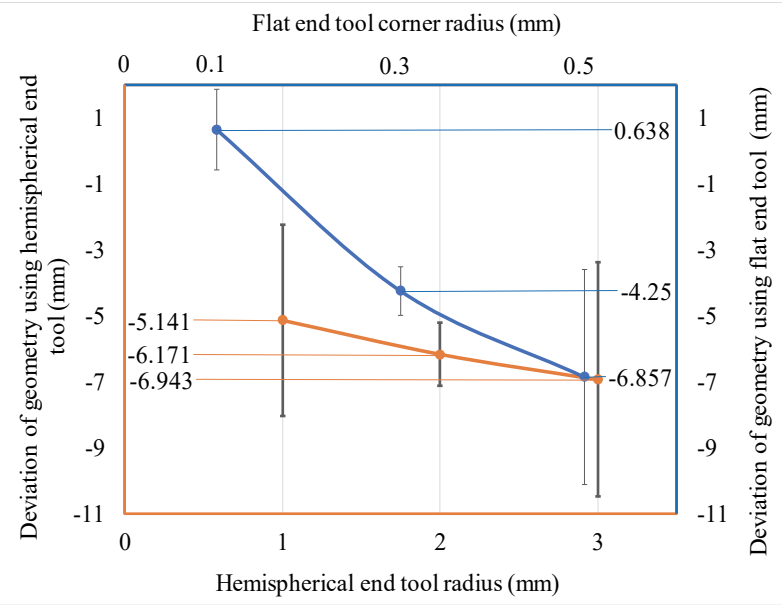

Figure 9 Accuracy using Flat end tool and Hemispherical end tool

\subsection{Pillow Effect}

The minimum of the pillow effect is observed in parts formed by a Flat end tool (corner radius: $0,1 \mathrm{~mm}$ ), and this effect increases with an increase of the corner of the Flat end resulting in a reduced contact area. A very large pillow (49,88 times bigger than the minimum value) appears in parts formed by a $0,5 \mathrm{~mm}$ Flat end tool (see Fig. 10) which is abnormal regarding the other formed parts. The Flat end tool creates a smaller pillow than the Hemispherical end tool because it drives the unformed sheet horizontally, especially when the unformed part is getting smaller and smaller during the process, as shown in Fig. 11. An increase in the pillow effect due to an increase of the touched curve area results from increasing the diameter of the Hemispherical end tool. Ambrogio et al. claimed that the pillow effect is strongly influenced by the tool diameter [29]. The behaviour of the pillow effect is in agreement with previous studies in [19].

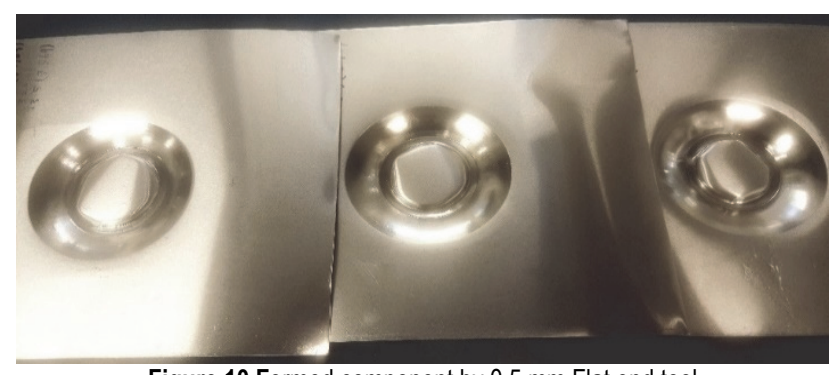

Figure 10 Formed component by $0,5 \mathrm{~mm}$ Flat end tool

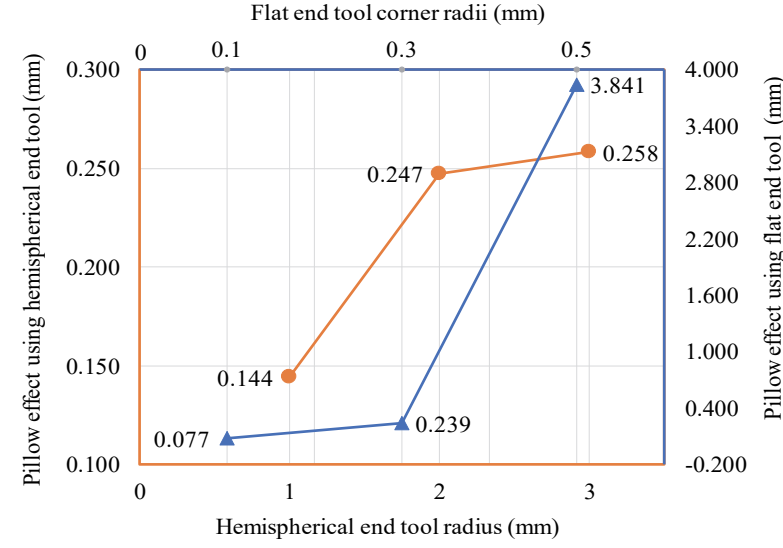

Figure 11 Pillow effect using Flat end tool and Hemispherical end tool

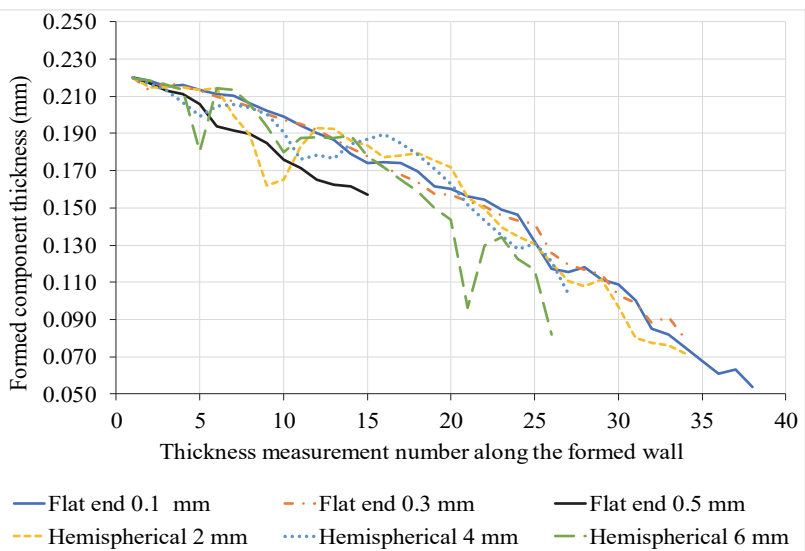

Figure 12 Thickness distribution using Flat end tool and Hemispherical end tool

\subsection{Thickness Homogeneity}

The thickness distribution can be considered as a threshold to evaluate the formability and success of a process [30]. Li et al. claimed - based on their simulationsthat the thickness at the end of the formed wall is smaller than in the middle of it, which can clarify that the crack always happens at the end of the component if excessive thinning is observed [30]. In order to identify the thickness distribution of the formed components, the thickness measurement was taken along the entire wall and the results in Fig. 12 show that the component formed by a smaller corner radius $0,1 \mathrm{~mm}$ reaches the highest stability in thickness distribution with the smallest values (it has the thinnest formed wall).

In the case of the Hemispherical end tool set the smallest diameter $(2 \mathrm{~mm})$ gives better stability. Due to the fact that "the deformation is a combination of shearing, bending and stretching" [31], the smaller diameter and smaller corner radius provide a small contact area and because the ISF is using local deformations, the thickness becomes more homogeneous based on the small amount of material subjected to the form.

\subsection{Formability (Maximum Depth)}

The final desired geometry comes from the path of the forming tool, and the shape of the tools significantly affects the SPIF formability. An experimental study was carried out by Bhattacharya and his co-author to obtain the formability for Al 5052 sheets [32]. They indicated that an increase in the tool diameter led to decreases in formability. 
However, as already mentioned, a more detailed summery on SPIF Formability with an observed threshold value is reported by Al-Ghamdi and Hussain [26]. Here, the previously reported ratio range is extended and it was found that higher formability (maximum depth) can be obtained by a smallest corner radius $(0,1 \mathrm{~mm})$ in the Flat tool set and the smallest diameter $(2 \mathrm{~mm})$ in the Hemispherical tool set (see Fig. 13).

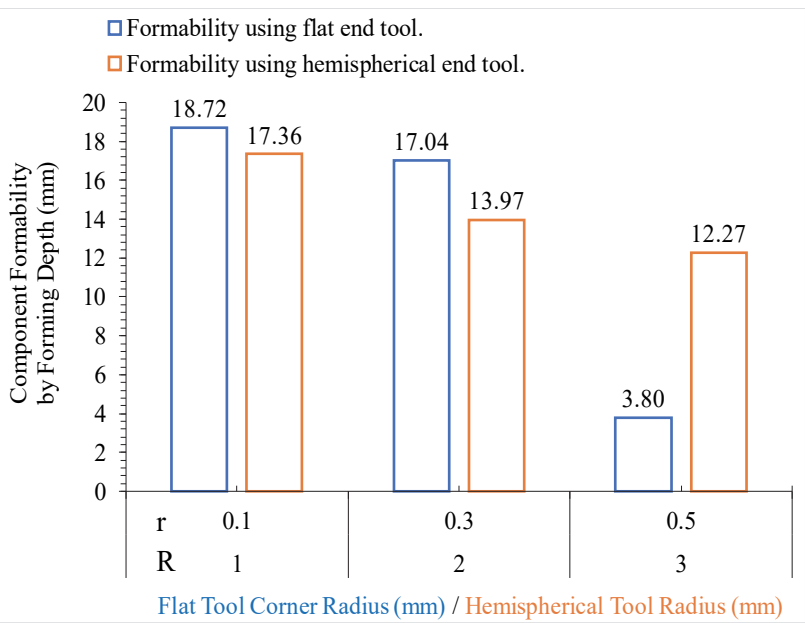

Figure 13 Component formability using Flat end tool and Hemispherical end tool

The ratio (between the tool diameter and the initial sheet thickness) and its decrease down to the threshold value seems to also be valid for sheets with an initial sheet thickness below $1 \mathrm{~mm}$. A summary of the maximum forming depth and the threshold ratios are listed in Tab. 4.

Table 4 Maximum. Forming depth and Ratio between the forming tool and the sheet thickness

\begin{tabular}{|c|c|c|c|}
\hline $\begin{array}{c}\text { Max. Forming } \\
\text { depth by Flat } \\
\text { end tool } \\
/ \mathrm{mm}\end{array}$ & $\begin{array}{c}\text { Ratio between } \\
\text { flat corner } \\
\text { radius and sheet } \\
\text { thickness } r / T_{\mathrm{B}}\end{array}$ & $\begin{array}{c}\text { Max. Forming } \\
\text { depth by } \\
\text { Hemispherical } \\
\text { end tool } \\
/ \mathrm{mm}\end{array}$ & $\begin{array}{c}\text { Ratio between } \\
\text { Hemispherical } \\
\text { radius and sheet } \\
\text { thickness } R / T_{\mathrm{B}}\end{array}$ \\
\hline 18,72 & 0,45 & 17,36 & 4,55 \\
\hline 17,04 & 1,36 & 13,97 & 9,09 \\
\hline 3,80 & 2,27 & 12,27 & 13,63 \\
\hline
\end{tabular}

\section{CONCLUSIONS}

In this paper, two different types of tool sets were applied to micro-SPIF. The tool diameter in the Hemispherical end tool and corner radius in the Flat end tool affects the accuracy of the geometry, pillow effect, thickness distribution, and can cause higher formability in the case where the $R / T_{\mathrm{B}}$ ratio is decreased down to a threshold value which is different for the Flat end tools. With the reported parameters it is shown that the Flat end tool minimizes $43 \%$ of the deviation of the geometric deflection compared to the Hemispherical end tool. The Flat end tool set gives a smaller bulging of the pillow effect than the Hemispherical end tool set $(49,88$ times bigger deviation is obtained by the largest corner radius of $0,5 \mathrm{~mm}$ than with the smallest corner radius of $0,1 \mathrm{~mm}$ ). An increase of the tool diameter/corner radius led to decreased formability. The highest stability in thickness distribution was achieved by the smallest corner radius of the flat end tool.

\section{Acknowledgements}

The research reported in this paper was supported by the Higher Education Excellence Program of the Ministry of Human Capacities in the frame of the Nanotechnology research area of Budapest University of Technology and Economics (BME FIKP-NANO) and by the GINOP-2.3.215-2016-00002 grant. The corresponding author would also like to thank TEMPUS Public Foundation for the StipendiumHungaricum Scholarship.

\section{REFERENCES}

[1] Leszak, E. (1967). Apparatus and Process for Incremental Dieless Forming. United States Patent Office, Patent No. $(3,342,051)$, U.S.

[2] Berghahn, W. G. (1967). Method of Dielessly Forming Surfaces of Revolution. United States Patent Office, Patent No. $(3,316,745)$, U.S.

[3] Franzen, V., Kwiatkowski, L., Martins, P., \& Tekkaya, A. (2009). Single point incremental forming of PVC. Journal of Materials Processing Technology, 209(1), 462-469. https://doi.org/10.1016/j.jmatprotec.2008.02.013

[4] Thangavel, K., Duraiswamy, R., Nagarajan, S., \& Ramasamy, S. (2019). Influence of Roller Ball Tool in Single Point Incremental Forming of Polymers. Tehnicki Vjesnik-Technical Gazette, 26(1). https://doi.org/10.17559/TV-20180809113703

[5] Mcanulty, T., Jeswiet, J., \& Doolan, M. (2017). Formability in single point incremental forming: A comparative analysis of the state of the art. CIRP Journal of Manufacturing Science and Technology, 16, 43-54. https://doi.org/10.1016/j.cirpj.2016.07.003

[6] Afonso, D., Sousa, R. A. D., \& Torcato, R. (2017). Incremental Forming of Tunnel Type Parts. Procedia Engineering, 183, 137-142. https://doi.org/10.1016/j.proeng.2017.04.036

[7] Kumar, A., Gulati, V., \& Kumar, P. (2018). Effects of Process Parameters on Surface Roughness in Incremental Sheet Forming. Materials Today: Proceedings, 5(14), 28026-28032. https://doi.org/10.1016/j.matpr.2018.10.043

[8] Hesse, D., Hoppe, F., \& Groche, P. (2017). Controlling Product Stiffness by an Incremental Sheet Metal Forming Process. Procedia Manufacturing, 10, 276-285. https://doi.org/10.1016/j.promfg.2017.07.058

[9] Bansal, A., Lingam, R., Yadav, S. K., \& Reddy, N. V. (2017). Prediction of forming forces in single point incremental forming. Journal of Manufacturing Processes, 28, 486-493. https://doi.org/10.1016/j.jmapro.2017.04.016

[10] Raju, C. \& Narayanan, C. S. (2015). FLD and Fractography Analysis of Multiple Sheet Single Point Incremental Forming. Transactions of the Indian Institute of Metals, 69(6), 1237-1243. https://doi.org/10.1007/s12666-015-0679-5

[11] Suresh, K., Khan, A., \& Regalla, S. P. (2013). Tool Path Definition for Numerical Simulation of Single Point Incremental Forming. Procedia Engineering, 64, 536-545. https://doi.org/10.1016/j.proeng.2013.09.128

[12] Durante, M., Formisano, A., Langella, A., \& Minutolo, F. M. C. (2009). The influence of tool rotation on an incremental forming process. Journal of Materials Processing Technology, 209(9), 4621-4626. https://doi.org/10.1016/j.jmatprotec.2008.11.028

[13] Ambrogio, G., Filice, L., \& Micari, F. (2006). A force measuring based strategy for failure prevention in incremental forming. Journal of Materials Processing Technology, 177(1-3), 413-416. https://doi.org/10.1016/j.jmatprotec.2006.04.076 
[14] Park, J. J. \& Kim, Y. H. (2003). Fundamental studies on the incremental sheet metal forming technique. Journal of Materials Processing Technology, 140(1-3), 447-453. https://doi.org/10.1016/S0924-0136(03)00768-4

[15] Kim, T. \& Yang, D. (2000). Improvement of formability for the incremental sheet metal forming process. International Journal of Mechanical Sciences, 42(7), 1271-1286. https://doi.org/10.1016/S0020-7403(99)00047-8

[16] Mulay, A., Ben, B. S., Ismail, S., Kocanda, A., \& Jasiński, C. (2018). Performance evaluation of high-speed incremental sheet forming technology for AA5754 H22 aluminum and DC04 steel sheets. Archives of Civil and Mechanical Engineering, 18(4), 1275-1287. https://doi.org/10.1016/j.acme.2018.03.004

[17] Paniti, I. \& Viharos, Z. J. (2017). Fracture diagnostics for single point incremental forming of thin aluminum alloy foils. 15th IMEKO TC10 Workshop on Technical Diagnostics 2017 - "Technical Diagnostics in CyberPhysical Era, "34-38.

[18] Verbert, J., Behera, A. K., Lauwers, B., \& Duflou, J. R. (2011). Multivariate Adaptive Regression Splines as a Tool to Improve the Accuracy of Parts Produced by FSPIF. Key Engineering Materials, 473, 841-846. https://doi.org/10.4028/www.scientific.net/KEM.473.841

[19] Ziran, X., Gao, L., Hussain, G., \& Cui, Z. (2009). The performance of flat end and hemispherical end tools in single-point incremental forming. The International Journal of Advanced Manufacturing Technology, 46(9-12), 11131118. https://doi.org/10.1007/s00170-009-2179-4

[20] Kim, Y. \& Park, J. (2002). Effect of process parameters on formability in incremental forming of sheet metal. Journal of Materials Processing Technology, 130-131, 42-46. https://doi.org/10.1016/S0924-0136(02)00788-4

[21] Jeswiet, J., Adams, D., Doolan, M., Mcanulty, T., \& Gupta, P. (2015). Single point and asymmetric incremental forming. Advances in Manufacturing, 3(4), 253-262. https://doi.org/10.1007/s40436-015-0126-1

[22] Durante, M., Formisano, A., \& Langella, A. (2010). Comparison between analytical and experimental roughness values of components created by incremental forming. Journal of Materials Processing Technology, 210(14), 19341941. https://doi.org/10.1016/j.jmatprotec.2010.07.006

[23] Nama, S. A., Namer, N. S. M., \& Najm, S. M. (2014). The Effect of using Grease on the Surface Roughness of Aluminum 1100 Sheet during the Single Point Incremental Forming Process. Journal of Trends in Machine Design, 1(1), 53-56. Retrieved from www.stmjournals.com

[24] Kurra, S. \& Regalla, S. (2015). Multi-objective optimisation of single point incremental sheet forming using Taguchibased grey relational analysis. International Journal of Materials Engineering Innovation, 6(1), 74 https://doi.org/10.1504/JJMATEl.2015.069802

[25] Centeno, G., Bagudanch, I., Martínez-Donaire, A., GarcíaRomeu, M., \& Vallellano, C. (2014). Critical analysis of necking and fracture limit strains and forming forces in single-point incremental forming. Materials \& Design, 63, 20-29. https://doi.org/10.1016/j.matdes.2014.05.066

[26] Al-Ghamdi, K. \& Hussain, G. (2015). Corrigendum to: "Threshold tool-radius condition maximizing the formability in SPIF considering a variety of materials: Experimental and FE investigations" Int. J. Mach. Tools Manuf. 88 (2015) 8294, International Journal of Machine Tools and Manufacture, 91, 115. https://doi.org/10.1016/j.ijmachtools.2014.12.005

[27] Avitzur, B. \& Yang, C. T. (1960). Analysis of Power Spinning of Cones. Journal of Engineering for Industry, 82(3), 231. https://doi.org/10.1115/1.3663052

[28] Hussain, G., Gao, L., \& Dar, N. (2007). An experimental study on some formability evaluation methods in negative incremental forming. Journal of Materials Processing Technology, 186(1-3), 45-53.

https://doi.org/10.1016/j.jmatprotec.2006.12.005

[29] Ambrogio, G., Cozza, V., Filice, L., \& Micari, F. (2007). An analytical model for improving precision in single point incremental forming. Journal of Materials Processing Technology, 191(1-3), 92-95. https://doi.org/10.1016/j.jmatprotec.2007.03.079

[30] Li, Y., Liu, Z., Daniel, W. B., \& Meehan, P. A. (2014). Simulation and Experimental Observations of Effect of Different Contact Interfaces on the Incremental Sheet Forming Process. Materials and Manufacturing Processes, 29(2), 121-128. https://doi.org/10.1080/10426914.2013.822977

[31] Liu, Z. \& Li, G. (2019). Single point incremental forming of $\mathrm{Cu}-\mathrm{Al}$ composite sheets: A comprehensive study on deformation behaviors. Archives of Civil and Mechanical Engineering, 19(2), 484-502. https://doi.org/10.1016/j.acme.2018.11.011

[32] Bhattacharya, A., Singh, S., Maneesh, K., Reddy, N. V., \& Cao, J. (2011). Formability and Surface Finish Studies in Single Point Incremental Forming. ASME 2011 International Manufacturing Science and Engineering Conference, 1. https://doi.org/10.1115/MSEC2011-50284

\section{Contact information:}

\section{Sherwan Mohammed NAJM}

(Corresponding author)

1) Department of Manufacturing Science and Engineering, Budapest University of Technology and Economics,

H-1111 Budapest, Mủegyetemrkp. 3., Hungary,

2) Kirkuk Technical Institute, Northern Technical University, Mosul, Iraq

E-mail: sherwan@manuf.bme.hu

\section{Imre PANITI}

1) Centre of Excellence in Production Informatics and Control, Institute for Computer Science and Control (SZTAKI),

H-1111 Budapest, Kende u. 13-17., Hungary,

2) Department of Manufacturing Science and Engineering, Budapest University of Technology and Economics,

H-1111 Budapest, Müegyetemrkp. 3., Hungary

E-mail: imre.paniti@sztaki.hu 